\title{
Impact of supine versus prone position on endoscopic retrograde cholangiopancreatography performance: a retrospective study
}

\author{
Osayande Osagiede ${ }^{a}$, Gabriel A. Bolaños ${ }^{b}$, Jordan Cochuytc, Luisa M. Cruz ${ }^{d}$, Paul T. Krönere, \\ Frank J. Lukens' ${ }^{e}$, Juan E. Corrale
}

Albert Einstein College of Medicine, New York, USA; University of South Alabama, Mobile, Alabama, USA; Mayo

Clinic, Jacksonville, Florida, USA; Universidad Francisco Marroquín, Guatemala City, Guatemala

\begin{abstract}
Background Endoscopic retrograde cholangiopancreatography (ERCP) is frequently performed in the prone or supine position. We compared the technical success and other outcomes between these positions.

Methods This was a retrospective cohort study using the Clinical Outcomes Research Initiative database. Demographics, procedure and fluoroscopy time, visualization of main structures, and technical success rates were compared between the supine and prone positions. Univariate and multivariate regressions were performed to adjust for age, sex, ethnicity and clinical setting.

Results A total of 21,090 patients who underwent ERCP were included, of whom 1769 (8.4\%) were supine and 19,321 (91.6\%) were prone. The common bile duct (CBD) was visualized and cannulated in $89.1 \%$ of supine vs. $91.4 \%$ of prone positions $(\mathrm{P}=0.017)$, while the ampulla was visualized in $97.1 \%$ of supine vs. $97.7 \%$ of prone $(\mathrm{P}=0.414)$. The ERCP was incomplete in $10 \%$ of supine vs. $5 \%$ of prone cases $(\mathrm{P}<0.001)$. On multivariate analysis, supine position required shorter procedure times than prone (adjusted odds ratio [aOR] 0.98, 95\% confidence interval [CI] 0.98$0.98 ; \mathrm{P}<0.001)$. The supine position also yielded lower odds of $\mathrm{CBD}$ visualization and cannulation (aOR 0.63, 95\%CI 0.44-0.91; $\mathrm{P}=0.011$ ) and higher odds of an incomplete examination (aOR 1.84, 95\%CI 1.46-2.30; $\mathrm{P}<0.001)$ vs. prone.

Conclusions The supine position leads to shorter procedures but is more likely to result in poorer visualization and cannulation of the $\mathrm{CBD}$ and an incomplete examination. This may reflect the technical difficulty of performing ERCP in the supine position for the endoscopist. Our study supports recommendations for an individualized ERCP approach.
\end{abstract}

Keywords ERCP, outcomes, biliary disease, endoscopy, techniques

Ann Gastroenterol 2021; 34 (2): 1-6

${ }^{a}$ Department of Medicine, Jacobi Medical Center, Albert Einstein College of Medicine, New York (Osayande Osagiede); 'bepartment of Medicine, University of South Alabama, Mobile, Alabama (Gabriel A. Bolaños); 'Department of Health Science Research, Mayo

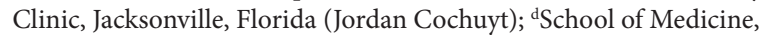
Universidad Francisco Marroquín, Guatemala City, Guatemala (Luisa M. Cruz); ${ }^{e}$ Division of Gastroenterology and Hepatology, Mayo Clinic, Jacksonville, Florida (Paul T. Kröner, Frank J. Lukens, Juan E. Corral), USA

Conflict of Interest: None

Correspondence to: Juan E. Corral, MD, 4500 San Pablo Rd S, Jacksonville, Florida, 32224 USA, e-mail: jcorralhu@phs.org

Received 27 July 2020; accepted 28 December 2020; published online 26 February 2021

DOI: https://doi.org/10.20524/aog.2021.0609

\section{Introduction}

Since its introduction 5 decades ago, endoscopic retrograde cholangiopancreatography (ERCP) has become a hugely popular and important diagnostic and therapeutic procedure for pancreatobiliary diseases [1-5]. Traditionally, ERCP has been performed in the prone and left lateral positions [2,6-8]. The prone position for ERCP has been favored because of the ease of visualization and cannulation of the biliary and pancreatic ducts [2,9]. Additionally, the prone position has been associated with a smaller risk of aspiration, relatively easy intubation of the gastrointestinal tract and may be more comfortable for the endoscopist [6]. The prone position for ERCP has also been associated with a lower risk of cardiopulmonary complications and better technical success rates [10]. The prone position has been traditionally favored by 
endoscopists, more so in view of the relative positional ease for the endoscopist in relation to the patient [6].

However, there are scenarios when the prone position for ERCP may not be ideal. In such scenarios, the supine position for ERCP has provided an effective alternative to the prone position. For example, the supine position has been favored when airway protection is desired, as in the case of ventilated patients in the intensive care unit (ICU) $[2,6]$. The supine position has also been used in cases where the patient is unable to lie prone because of abdominal distension, ascites, recent abdominal surgery, indwelling percutaneous tubes or catheters, pregnancy, morbid obesity, or anatomical anomalies $[2,9,11]$.

Although a few studies have demonstrated similar clinical outcomes between supine and prone positions for ERCP performance $[12,13]$, the vast majority of ERCPs are still performed in the prone position. It is unclear whether this trend is related to endoscopist comfort and familiarity with the prone position alone, or may be influenced by differences in ERCP performance between both positions. As a result, the impact of patient position on the ERCP procedure has remained a matter of debate and there is no clear consensus on which position is associated with better outcomes. Previous studies that have examined the relationship between patient position and ERCP outcomes were limited by sample size, lacked diversity in the indications for the ERCP, or were limited to a single-center or single-endoscopist experience [9,12-14].

While prospective data would be ideal to further examine the differences in ERCP performance between supine and prone positions, prospective data on this subject remain extremely limited. Therefore, we sought to compare the technical success of ERCP between supine and prone positions retrospectively using a large national database comprising more than a decade of procedures completed across the United States.

\section{Materials and methods}

We conducted a retrospective cohort study using the Clinical Outcomes Research Initiative (CORI) database from the National Institute of Diabetes and Digestive and Kidney Diseases Central Repository [15]. The CORI was launched in 1995 and is the largest multicenter endoscopic database in the United States. Approximately 500 physicians from 65 adult and 12 pediatric practice sites submit more than 250,000 reports annually to a central data repository. The practice sites include private practice (70-75\% of the reports), academic sites (10-15\%), and Veterans Affairs sites (11\%). They were selected to represent a complete spectrum of gastroenterology practices and include both urban and rural sites across the country. Approximately $95 \%$ of procedures reported by the CORI are performed in outpatient settings. The CORI Endoscopic Reporting Software has 2 major versions, V3 and V4, in use from 2000-2012 and 2012-2014, respectively. Additional details about CORI can be found elsewhere [15].

The CORI database Version 3 was reviewed to capture all ERCPs performed for all indications between January 2000 and December 2012. ERCP cases in adults ( $\geq 18$ years) were reviewed if the endoscopist had included a description of position according to the CORI software. Patients were included if their age, sex, procedure setting (inpatient, outpatient or ICU) and a description of patient position (supine or prone) were available. Patients with positions other than supine or prone were excluded. Demographic variables, procedure indications and fluoroscopic findings (e.g., visualization and cannulation of the common bile duct [CBD] and pancreatic duct) were documented. Our primary outcome was technical success (i.e., complete or incomplete examination, selfreported by endoscopist). Our secondary outcomes were ampulla visualization (i.e., percentage of cases), procedure time (i.e., from scope insertion to withdrawal), and fluoroscopy time.

Complete and incomplete examinations as used in our study were self-reported variables by the endoscopists and are not limited to successful or failed cannulation, but also included success or failure to achieve diagnostic or therapeutic goals including stone extraction, stent placements, tissue biopsy, etc. The endoscopists performing ERCP in the CORI database were board-certified gastroenterologists who have training and experience in the procedure. The endoscopists included were those identified as "responsible endoscopist" at the time of the procedure. If a trainee is present for the procedure, for example at academic medical centers, the trainee is identified, but it is not certain who actually performed the procedure when a trainee is present.

Categorical variables were compared using Pearson's chisquare test and continuous variables using a standard $t$-test. Univariate regression was performed, followed by a multivariate regression model with significant variables $(\mathrm{P}<0.05)$. Crude odds ratios and adjusted odds ratio (aOR) were reported for each variable. For logistic regression, we only included procedures that had complete information on the variable of interest, namely, ERCP technical success, defined as complete examination (with normal and abnormal findings). Analyses were performed using SAS version 9.4 (SAS Institute, North Carolina, US). Our research protocol was exempt from a formal institutional review board approval since it involved analysis of de-identified information. No patients were contacted during this study.

\section{Results}

A total number of 21,090 patients who underwent ERCP in the study period were identified (Fig. 1). Of these, 1769 (8.4\%) were supine and 19,321 (91.6\%) were prone. Overall, the mean patient age was 57 years and $52 \%$ were male.

Significant differences were observed in the demographic and clinical characteristics of prone and supine ERCP patients (Table 1). A greater proportion of male patients underwent ERCP in prone position vs. supine position ( $52.7 \%$ vs. $45.7 \%$, $\mathrm{P}<0.001)$. Asians (3.8\% vs. $1.5 \%, \mathrm{P}<0.001)$, Hispanics $(37.9 \%$ vs. $10.4 \%, \mathrm{P}<0.001)$, and African Americans $(12.4 \%$ vs. $7.8 \%$, $\mathrm{P}<0.001)$ were more likely to undergo ERCP in supine vs. prone position. Whites $(73.1 \%$ vs. $43.4 \%, \mathrm{P}<0.001)$ were more likely to undergo ERCP in prone vs. supine position.

In terms of the clinical setting in which ERCP was performed, $46 \%$ were in outpatient, $42.2 \%$ in inpatient and $2.2 \%$ in ICU settings. ERCP procedures performed in outpatient $(47.9 \%$ vs. $24.9 \%, \mathrm{P}<0.001)$ and inpatient $(42.5 \%$ vs. $39.0 \%, \mathrm{P}<0.001)$ 


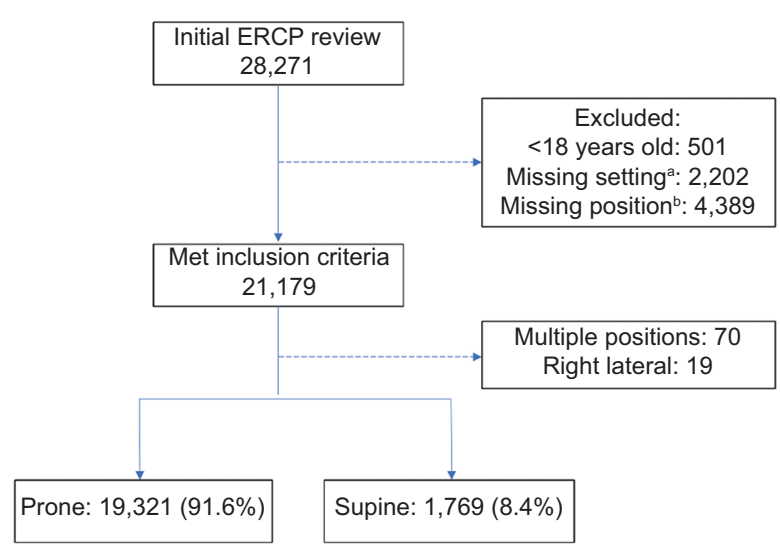

Figure 1 Patient inclusion flow diagram a. Setting: inpatient, outpatient, ICU, etc. b. Position: supine, prone, left-lateral, etc. ERCP, endoscopic retrograde cholangiopancreatography

settings were more likely to be performed in prone vs. supine position, respectively. ERCPs in the ICU were more likely to be performed in supine vs. prone position $(3.2 \%$ vs. $2.1 \%, \mathrm{P}<0.001)$.

Table 2 shows differences in indications and findings for ERCP between supine and prone patients. Overall, patients who underwent an ERCP in the prone position were more likely to have it performed for an abnormal imaging study and to have a normal examination or ductal dilation. Patients who completed their ERCP in then supine position were more likely to have abdominal pain or bloating and to have fewer stones, stents or undetermined filling defects.

The average procedure time for the supine position was 29.7 vs. $39.8 \mathrm{~min}$ for prone $(\mathrm{P}<0.001)$. The average fluoroscopy time was 6.9 and $6.3 \mathrm{~min}$ for supine and prone positions, respectively $(\mathrm{P}=0.187)$. The ampulla was visualized in $97.1 \%$ of supine cases vs. $97.7 \%$ of prone cases $(\mathrm{P}=0.414)$. The $\mathrm{CBD}$ was visualized and cannulated in $89.1 \%$ of supine cases vs. $91.4 \%$ of prone cases $(\mathrm{P}=0.017)$. The ERCP was incomplete in $10 \%$ of supine cases vs. $5 \%$ of prone cases $(\mathrm{P}<0.001)$.

Additional differences were noted in the multiple logistic regression model. Table 3 shows the crude and adjusted odds ratios for ERCP outcomes associated with the supine position. Patients who underwent ERCP in the supine position had shorter procedure times (aOR $0.98,95 \%$ confidence interval [CI] 0.98-0.98; $\mathrm{P}<0.001)$ vs. the prone position. Supine patients also had lower odds of CBD visualization and cannulation (aOR 0.63 , 95\%CI 0.44-0.91; $\mathrm{P}=0.011$ ) than prone patients. Patients who underwent ERCP in the supine position displayed higher odds of an incomplete ERCP examination (aOR 1.84, 95\%CI 1.46$2.30 ; \mathrm{P}<0.001)$ vs. the prone position. There were no statistically significant differences between supine and prone positions in terms of fluoroscopy time or the visualization of the ampulla.

\section{Discussion}

Our study sought to assess the impact of patient position on ERCP performance, in terms of technical success rates compared between supine and prone positions. To our knowledge, this is the largest study of this nature to date. We found that the majority of ERCPs (91.6\%) were performed in the prone position. In terms of clinical settings, ERCPs in the ICU were more likely to be performed in the supine position, in contrast to inpatient and outpatient settings, in which the prone position was favored. Initial visualization of the major papilla or ampulla was similar in both groups. However, cannulation was more difficult in the supine position, as measured by visualization and cannulation rates of the CBD. Finally, regarding the technical success of ERCP, patients who underwent ERCP in the supine position had higher odds of an incomplete ERCP examination.

In the years since its introduction, ERCP has increasingly become a therapeutic rather than a diagnostic tool for pancreatobiliary pathologies [2]. Regardless of the indication, the technical success of the procedure remains an important endpoint for all ERCP procedures. In this study, technical success was self-recorded by the endoscopist, defined as a complete examination, regardless of whether the findings were normal or abnormal. Our study found that patients who underwent ERCP in the supine position were more likely to have an incomplete ERCP examination. The findings of previous studies that have examined ERCP position and technical success rates have been diverse. In a recent meta-analysis (which included 3 abstracts and 3 published papers), the authors compared the technical success and safety outcomes of ERCP in prone vs. supine position [10]. Not only was the pooled technical success slightly higher in the prone ERCP position, there were also fewer complications observed. However, the heterogeneity of the studies analyzed in terms of sample size and the diverse nature of the studies were notable limitations of the meta-analysis $[2,10]$.

The finding that procedures performed in the prone position were more frequently successful but required a longer procedure time on average can be misleading. Previous studies have reported no difference in procedure time between supine and prone positions [12-14]. Our analysis did not record how many patients required orotracheal intubation in each position. From the authors' personal experience, and published literature, in the last 20 years only a few centers in the United States perform ERCP procedures without orotracheal intubation [16]. We hypothesize that the additional time seen in prone procedures was used to rotate and reposition the patient after intubation, once the procedure was completed. Once cannulation was achieved and a guidewire was secured into the biliary or pancreatic ducts such differences would dissipate, as the fluoroscopy time used for both groups showed no difference.

When assessing the 3 major prior studies individually, Terruzzi et al, in a prospective randomized study that evaluated 34 ERCP patients, concluded that ERCP in supine position was technically more demanding for endoscopists and carries a greater risk of adverse cardiorespiratory events [14]. In contrast, Tringali et al studied 120 ERCP patients in another prospective randomized study, and found no difference between supine and prone positions in terms of procedural success, technical difficulty, and complications [13]. Similarly, in a retrospective study by Ferreira and Baron that evaluated 649 ERCP patients, the authors found that success and complication rates were similar for both groups, although 
Table 1 Patient demographic and clinical characteristics

\begin{tabular}{|c|c|c|c|c|}
\hline Variable & Prone $(\mathrm{N}=19321)$ & Supine $(\mathrm{N}=1769)$ & Total $(\mathrm{N}=21090)$ & $\mathrm{P}$-value \\
\hline $\begin{array}{l}\text { Age (years) } \\
\text { Mean (SD) }\end{array}$ & $56.9(18.8)$ & $58.0(18.8)$ & $57.0(18.8)$ & 0.024 \\
\hline $\begin{array}{l}\text { Sex } \\
\quad \text { Female } \\
\text { Male }\end{array}$ & $\begin{array}{c}9148(47.3 \%) \\
10173(52.7 \%)\end{array}$ & $\begin{array}{l}960(54.3 \%) \\
809(45.7 \%)\end{array}$ & $\begin{array}{l}10108(47.9 \%) \\
10982(52.1 \%)\end{array}$ & $<0.001$ \\
\hline $\begin{array}{l}\text { Ethnicity } \\
\text { Asian } \\
\text { Hispanic } \\
\text { Native American } \\
\text { Non-Hispanic Black } \\
\text { Non-Hispanic White } \\
\text { Other }\end{array}$ & $\begin{array}{c}293(1.5 \%) \\
2012(10.4 \%) \\
1178(6.1 \%) \\
1515(7.8 \%) \\
14129(73.1 \%) \\
37(0.2 \%)\end{array}$ & $\begin{array}{c}68(3.8 \%) \\
671(37.9 \%) \\
34(1.9 \%) \\
219(12.4 \%) \\
767(43.4 \%) \\
4(0.2 \%)\end{array}$ & $\begin{array}{c}361(1.7 \%) \\
2683(12.7 \%) \\
1212(5.7 \%) \\
1734(8.2 \%) \\
14896(70.6 \%) \\
41(0.2 \%)\end{array}$ & $<0.001$ \\
\hline $\begin{array}{l}\text { Setting } \\
\text { ICU } \\
\text { Inpatient } \\
\text { Outpatient }\end{array}$ & $\begin{array}{c}399(2.1 \%) \\
8215(42.5 \%) \\
9253(47.9 \%)\end{array}$ & $\begin{array}{c}56(3.2 \%) \\
690(39.0 \%) \\
440(24.9 \%)\end{array}$ & $\begin{array}{c}455(2.2 \%) \\
8905(42.2 \%) \\
9693(46.0 \%)\end{array}$ & $<0.001$ \\
\hline $\begin{array}{l}\text { Procedure time (min) } \\
\text { Mean (SD) }\end{array}$ & $39.8(24.4)$ & $29.7(22.4)$ & $38.9(24.4)$ & $<0.001$ \\
\hline $\begin{array}{l}\text { Fluoroscopy time (min) } \\
\text { Mean (SD) }\end{array}$ & $6.3(6.5)$ & $6.9(6.0)$ & $6.3(6.5)$ & 0.187 \\
\hline $\begin{array}{l}\text { Ampulla (major papilla) visualization } \\
\text { Not sought } \\
\text { Not visualized } \\
\text { Visualized }\end{array}$ & $\begin{array}{c}117(0.8 \%) \\
232(1.5 \%) \\
14956(97.7 \%)\end{array}$ & $\begin{array}{c}9(0.9 \%) \\
20(2.0 \%) \\
965(97.1 \%)\end{array}$ & $\begin{array}{c}126(0.8 \%) \\
252(1.5 \%) \\
15921(97.7 \%)\end{array}$ & 0.414 \\
\hline $\begin{array}{l}\text { Minor papilla visualization } \\
\text { Not sought } \\
\text { Not visualized } \\
\text { Visualized }\end{array}$ & $\begin{array}{l}8985(75.9 \%) \\
1282(10.8 \%) \\
1574(13.3 \%)\end{array}$ & $\begin{array}{l}406(72.9 \%) \\
67(12.0 \%) \\
84(15.1 \%)\end{array}$ & $\begin{array}{l}9391(75.7 \%) \\
1349(10.9 \%) \\
1658(13.4 \%)\end{array}$ & 0.272 \\
\hline $\begin{array}{l}\text { CBD visualization and cannulation } \\
\text { Not sought } \\
\text { Not visualized } \\
\text { Visualized }\end{array}$ & $\begin{array}{c}396(2.5 \%) \\
977(6.1 \%) \\
14621(91.4 \%)\end{array}$ & $\begin{array}{c}40(3.6 \%) \\
81(7.3 \%) \\
990(89.1 \%)\end{array}$ & $\begin{array}{c}436(2.5 \%) \\
1058(6.2 \%) \\
15611(91.3 \%)\end{array}$ & 0.017 \\
\hline $\begin{array}{l}\text { ERCP technical success } \\
\text { Complete - abnormal findings } \\
\text { Complete - normal findings } \\
\text { Incomplete }\end{array}$ & $\begin{array}{c}11904(82.5 \%) \\
1798(12.5 \%) \\
733(5.0 \%)\end{array}$ & $\begin{array}{l}830(79.9 \%) \\
105(10.1 \%) \\
104(10.0 \%)\end{array}$ & $\begin{array}{c}12734(82.3 \%) \\
1903(12.3 \%) \\
837(5.4 \%)\end{array}$ & $<0.001$ \\
\hline
\end{tabular}

${ }^{a}$ Chi square for categorical variables, $t$-test for continuous variables, statistically significant $(\mathrm{P}<0.05)$

$I C U$, intensive care unit; $C B D$, common bile duct; ERCP, endoscopic retrograde cholangiopancreatography

the degree of procedural difficulty was significantly higher in the supine group [12]. The study by Ferreira and Baron had the advantage of a larger sample size, but it was limited to a single-endoscopist experience and procedures performed for a biliary indication only (excluding pancreatography and other interventions) [12]. The heterogeneity of these studies, including ours, in terms of ERCP technical success is explained in part by the varying definition of what constitutes ERCP technical or clinical success. It may also be explained by the differences in the physicians' training, experience and comfort level with different patient positions.

The ease of visualization and cannulation of the ampulla is a major concern for an endoscopist planning to perform an ERCP. In this regard, the prone position (or left-lateral prone variation) has traditionally been favored because of the presumed ease of visualization and cannulation based on the experience of ERCP experts. Historically, biliary and pancreatic cannulation is technically more challenging in a supine position [2,9]. Our study found no significant difference in the ampulla visualization between the 2 positions for ERCP. Indeed, the rates of ampulla visualization were considerably high for both ERCP positions (97.1\% vs. 97.7\%). Despite adequate visualization of the ampulla, cannulation of the bile duct was lower in the prone position in comparison to supine $(89.1 \%$ vs. $91.4 \%, \mathrm{P}=0.017)$. In similar studies, failed biliary cannulation in the supine position became successful after patients were moved to the prone position [14]. In contrast, no differences in ductal cannulation were observed between supine and prone positions in the studies by Tringali et $a l$ and Ferreira and Baron [12,13]. Proper positioning of the ampulla of Vater in the right axis, proper orientation of the sphincterotome using the right guide/glide wire, gentle handling of the ampulla during cannulation, all are critical technical factors that determine successful visualization and selective cannulation of the biliary or pancreatic ducts [2]. Thus, patient 
Table 2 Primary indications and findings for endoscopic retrograde cholangiopancreatography

\begin{tabular}{|c|c|c|c|}
\hline Variable & Prone $(\mathrm{N}=18681)$ & Supine $(N=1247)$ & P-value \\
\hline Procedure indication $^{\mathrm{b}}$ & & & $<0.001$ \\
\hline Abdominal pain or bloating & $7364(39.4 \%)$ & $591(47.4 \%)$ & 0.400 \\
\hline Jaundice & $6002(32.1 \%)$ & $415(33.3 \%)$ & $<0.001$ \\
\hline Abnormal imaging & $6116(32.7 \%)$ & $199(15.9 \%)$ & 0.011 \\
\hline Fever or chills & $1702(9.1 \%)$ & $87(7.0 \%)$ & 0.001 \\
\hline Nausea & $1144(6.1 \%)$ & $47(3.8 \%)$ & \\
\hline \multicolumn{4}{|l|}{ Procedure findings ${ }^{\mathrm{b}}$} \\
\hline Ductal dilation & $6265(33.5 \%)$ & $357(28.6 \%)$ & $<0.001$ \\
\hline Normal exam & $5171(27.7 \%)$ & $297(23.8 \%)$ & 0.003 \\
\hline Biliary stones & $4517(24.2 \%)$ & $286(22.9 \%)$ & 0.320 \\
\hline Previous stent (removal or exchange) & $4447(23.8 \%)$ & $249(20.0 \%)$ & 0.002 \\
\hline Filling defect (undetermined) & $1771(9.5 \%)$ & $75(6.0 \%)$ & $<0.001$ \\
\hline
\end{tabular}

${ }^{a}$ Chi square, statistically significant $(\mathrm{P}<0.05)$

${ }^{b}$ Indications and findings are not mutually exclusive

Table 3 Crude and adjusted odds ratios for ERCP outcomes associated with supine position (in comparison with prone position)

\begin{tabular}{|c|c|c|c|c|}
\hline Variable & Crude OR $(95 \% \mathrm{CI})$ & P-value & Adjusted OR (95\%CI) & $\mathrm{P}$-value \\
\hline Procedure time $^{\mathrm{a}}$ & $0.975(0.972-0.978)$ & $<0.001$ & $0.979(0.976-0.982)$ & $<0.001$ \\
\hline Fluoroscopy time $^{a}$ & $1.012(0.993-1.029)$ & 0.187 & $1.009(0.989-1.027)$ & 0.348 \\
\hline $\begin{array}{l}\text { Ampulla visualization } \\
\text { Not sought } \\
\text { Not visualized } \\
\text { Visualized }\end{array}$ & $\begin{array}{c}1 \\
1.121(0.508-2.659) \\
0.839(0.450-1.785)\end{array}$ & $\begin{array}{l}0.785 \\
0.613\end{array}$ & $\begin{array}{c}1 \\
1.355(0.594-3.316) \\
1.106(0.574-2.413)\end{array}$ & $\begin{array}{l}0.484 \\
0.781\end{array}$ \\
\hline $\begin{array}{l}\text { CBD visualization and cannula } \\
\text { Not sought } \\
\text { Not visualized } \\
\text { Visualized }\end{array}$ & $\begin{array}{c}1 \\
0.821(0.556-1.230) \\
0.670(0.488-0.948)\end{array}$ & $\begin{array}{l}0.329 \\
0.018\end{array}$ & $\begin{array}{c}1 \\
0.765(0.504-1.178) \\
0.627(0.444-0.909)\end{array}$ & $\begin{array}{l}0.215 \\
0.011\end{array}$ \\
\hline $\begin{array}{l}\text { ERCP technical success } \\
\text { Complete - abnormal } \\
\text { Complete - normal findings } \\
\text { Incomplete }\end{array}$ & $\begin{array}{c}1 \\
0.838(0.676-1.027) \\
2.035(1.630-2.517)\end{array}$ & $\begin{array}{c}0.096 \\
<0.001\end{array}$ & $\begin{array}{c}1 \\
0.966(0.774-1.195) \\
1.841(1.460-2.302)\end{array}$ & $\begin{array}{c}0.755 \\
<0.001\end{array}$ \\
\hline
\end{tabular}

${ }^{\mathrm{a} B a s e d}$ on increasing time intervals

$O R$, odds ratio; CI, confidence interval; $C B D$, common bile duct; ERCP, endoscopic retrograde cholangiopancreatography

position is likely to be of less significance when these technical considerations are satisfied. Additionally, appropriate positioning of the endoscopist in relation to video and fluoroscopy monitors can make ERCP in the supine position easier [17].

Among the practical challenges of performing ERCP in the supine position is the endoscopist's positioning in relation to the patient, requiring him or her to face away from the patient because of the camera orientation in the scopes $[6,10]$. This challenge is absent in the prone position. As a result, the prone position has been described to be more comfortable for endoscopists, therefore increasing the likelihood of technical success [10].

Finally, sex and ethnicity differences were noted between the supine and prone positions. Our study found that female patients were more likely to undergo ERCP in the supine position compared to their male counterparts. Additionally, patients of minority ethnicities, such as Asians, Hispanics and African Americans, were proportionally more likely to undergo ERCP in the supine than in the prone position. We hypothesize that the sex difference is related to sex-specific considerations, such as pregnancy, for which the supine position would be more appropriate. Further research is needed to confirm if there are significant ethnicity differences between supine and prone ERCP positions.

The strength of our study is that it utilized a large national database, thus overcoming the limitations of sample size and statistical power notable in prior studies. The study also captures the experiences of numerous endoscopists of varying expertise and backgrounds over a decade, thus increasing the generalizability of the findings. Our study has important limitations inherent to a retrospective review. Our results are subject to selection bias and lack the ability to account for causality. Multiple factors influence the choice of patient positions, such as endoscopist's experience, previous success in a certain procedure (e.g., patients requiring recurrent stent exchange), body mass index, abdominal problems (e.g., drains, tubes and ostomies), previous surgeries, respiratory capacity, all of which would been valuable to stratify our analysis further. Our study did not evaluate separately ERCPs performed for pancreatic indications. Pancreatography is technically more challenging and requires a different approach. Considering the small percentage of these procedures in our sample, and the 
similarity in minor ampulla visualization rates, we assumed our results would not be affected substantially by removing them. Finally, ERCP complications and medication use are not consistently recorded in the CORI database and were not included in our study design. Some have also argued that CORI may not be representative of endoscopic practice in the United States, and have criticized it for lack of image documentation, and incomplete patient history or procedure complications, all of which would have been trained to perform ERCP useful for this study [18].

In conclusion, most endoscopists have been trained performing ERCP with the patient in the prone position. Hence, the supine position is largely reserved for patients in the ICU, the pregnant or the morbidly obese. Previous studies to examine the role of patient position on ERCP outcomes have been limited either by sample size, or by a single-center or single-endoscopist experience. Our results support the concept that supine ERCP is technically more challenging, with lower cannulation rates and more incomplete cases. We hypothesize that the differences most probably reflect the technical difficulties of working in the supine position from an endoscopist's perspective. Our study adds incremental evidence to recommendations for an individualized ERCP approach based on the endoscopist's comfort level and the overall clinical scenario.

\section{Acknowledgment}

This manuscript was not prepared in collaboration with the CORI group and does not necessarily reflect the opinions or views of the CORI group, the National Institute of Diabetes and Digestive and Kidney Diseases (NIDDK) Central Repositories or the NIDDK (Data request Id 20888)

\section{References}

1. McCune WS, Shorb PE, Moscovitz H. Endoscopic cannulation of the ampulla of Vater: a preliminary report. Ann Surg 1968;167: 752-756.

2. Maydeo A, Patil GK. ERCP: does patient position count? Endosc Int Open 2018;6:E1302-E1303.

3. Maple JT, Ben-Menachem T, Anderson MA, et al; ASGE Standards of Practice Committee. The role of endoscopy in the evaluation of suspected choledocholithiasis. Gastrointest Endosc 2010;71:1-9.

4. Baron TH, Mallery JS, Hirota WK, et al. The role of endoscopy in the evaluation and treatment of patients with pancreaticobiliary malignancy. Gastrointest Endosc 2003;58:643-649.

5. Costamagna G, Shah SK, Tringali A. Current management of postoperative complications and benign biliary strictures. Gastrointest Endosc Clin N Am 2003;13:635-648, ix.

6. Wilcox, C. Should patients undergoing ERCP be placed in the prone or supine position? Nat Clin Prac Gastroenterol Hepatol 2008;5:488-489.

7. Park TY, Choi SH, Yang YJ, et al. The efficacy and safety of the left lateral position for endoscopic retrograde cholangiopancreatography. Saudi J Gastroenterol 2017;23:296-302.

8. Froehlich F. Patient position during ERCP: prone versus supine. What about left lateral throughout? Endoscopy 2006;38:755.

\section{Summary Box}

\section{What is already known:}

- Most endoscopists are trained to perform endoscopic retrograde cholangiopancreatography (ERCP) in the prone and left lateral positions

- The use of the supine position is currently limited to conditions such as recent abdominal surgery, morbid obesity, pregnancy and expected barriers to safe ventilation

- Some studies reported that the supine position is technically more demanding and carries a greater risk for complications

\section{What the new findings are:}

- Patients who underwent ERCP in the supine position had shorter procedure times

- Although initial visualization of the major papilla was similar in both groups, cannulation of the common bile duct was more difficult in the supine position

- Patients who underwent ERCP in the prone position were more likely to have a complete ERCP

9. Das A. Performing an ERCP with the patient in the supine position: necessity is the mother of improvisation. Gastrointest Endosc 2008;67:1044-1045.

10. Mashiana H, Jayaraj M, Mohan B, et al. Comparison of outcomes for supine vs prone position ERCP: a systematic review and metaanalysis. Endosc Int Open 2018;6:E1296-E1301.

11. Byun JR, Jahng JH, Song JC, Yu JS, Lee DK. Supine position endoscopic retrograde cholangiopancreatography in a patient with situs ambiguous with polysplenia. Dig Endosc 2010;22:322-324.

12. Ferreira LE, Baron TH. Comparison of safety and efficacy of ERCP performed with the patient in supine and prone positions. Gastrointest Endosc 2008;67:1037-1043.

13. Tringali A, Mutignani M, Milano A, Perri V, Costamagna G. No difference between supine and prone position for ERCP in conscious sedated patients: a prospective randomized study. Endoscopy 2008;40:93-97.

14. Terruzzi V, Radaelli F, Meucci G, Minoli G. Is the supine position as safe and effective as the prone position for endoscopic retrograde cholangiopancreatography? A prospective randomized study. Endoscopy 2005;37:1211-1214.

15. NIDDK Central Repository. Clinical Outcomes Research Initiative (CORI) [Internet]. Bethesda (MD): National Institute of Diabetes and Digestive and Kidney Diseases; c2018. Available from: https:// repository.niddk.nih.gov/studies/cori/ [Accessed 5 February 2021].

16. Lichtenstein DR, Jagannath S, Baron TH, et al; Standards of Practice Committee of the American Society for Gastrointestinal Endoscopy. Sedation and anesthesia in GI endoscopy. Gastrointest Endosc 2008;68:815-826.

17. Diehl D. Supine patient positioning for ERCP: indications and outcomes [abstract]. Gastrointest Endosc 2006;63:PAB291.

18. Ramsey PJ, Shaib YH, Graham DY. Appropriate use or overutilization of the CORI database? Am J Gastroenterol 2009;104:785-786. 